\title{
Electrodialysis concentration of sulfuric acid
}

\section{S.A. Loza* (D), N.A. Smyshlyaev, A.N. Korzhov, N.A. Romanyuk}

Kuban State University, Stavropolskaya St., 149, Krasnodar, 350049, Russia

* Corresponding author: s_loza@mail.ru

This article belongs to the PCEE-2020 Special Issue.

(C) 2021, The Authors. This article is published in open access form under the terms and conditions of the Creative Commons Attribution (CC BY) license (http://creativecommons.org/licenses/by/4.0/).

\section{Abstract}

An urgent task is the development of new resource-saving technologies for deep processing of wastes from the hydrometallurgical industry for the purpose of their reuse. Membrane technologies make it possible to create closed technological cycles with the reuse of recovered components in production, which allows solving many environmental problems. At the Abinsk Electric Steel Works Ltd. (Russia), during the production of copper-coated steel wire, a large amount of waste containing sulfuric acid and heavy metal salts is generated. The chemical treatment of such effluents with slaked lime and alkali produces a large amount of sludge, which causes environmental problems and leads to the irreversible loss of sulfuric acid. The problem of separating acids and salts can be solved using diffusion dialysis through anion-exchange membranes, however, to return the acid to the production cycle, the purified acid must be additionally concentrated. In this work, we studied the process of electrodialysis concentration of sulfuric acid using heterogeneous ion-exchange membranes Ralex ${ }^{\circledR}$ CMHPP and Ralex ${ }^{\circledR}$ AMHPP (manufactured by MEGA a.s., Czech Republic) which have a polypropylene reinforcing mesh resistant to acids. The main parameters of the electrodialysis concentration process have been determined - the dependence of the concentration of the regenerated sulfuric acid on the concentration at the inlet to the electrodialysis cell and on the current density, as well as the energy consumption for the process. It is shown that with the help of electrodialysis concentration it is possible to obtain sulfuric acid with a concentration of up to $180 \mathrm{~g} / \mathrm{L}$, which makes it possible to return it to the production cycle.

\section{Keywords}

ion exchange membrane diffusion dialysis electrodialysis concentration sulfuric acid recovery
Received: 31.12.2020

Revised: 30.03.2021

Accepted: 30.03.2021

Available online: 31.03 .2021

\section{Introduction}

One of the urgent tasks of the industry is the development of new resource-saving technologies for the deep processing of wastes from the metallurgical industry for the purpose of their reuse. The key task in solving the problem of protecting the environment and creating closed technological cycles is the development of effective methods for separating technological mixtures into components and further concentrating the resulting solutions.

Typical waste products from the hydrometallurgical industry are acidic effluents containing heavy metal salts. Currently, industrial wastewater treatment is most often performed using chemical precipitation methods. This method is relatively cheap and undemanding from a technological point of view. Purification of acidic effluents is carried out by adding slaked lime, sodium hydroxide and soda, followed by the separation of precipitation [1]. However, this cleaning method has a lot of disadvantages precipitated substances can dissolve after their disposal, which leads to secondary pollution of the environment. It is also negative that the amount of sludge formed significantly exceeds the amount of contamination in waste water, and acids are irretrievably lost as a result of the neutralization reaction.

The problem of disposal of the resulting acidic waste can be solved using membrane methods, which are currently widely used for purification, separation and concentration of technological solutions and gas mixtures. They allow you to create environmentally friendly, waste-free, energy-saving technological processes that can be easily automated, facilitating the solution of many social and 
environmental problems. The number of scientific publications on this topic has increased significantly in recent years [2]. Also, in recent time, the number of industries using electrodialysis technologies has grown significantly [3]. Most often, for processing solutions containing ionic impurities, the method of electrodialysis with ionexchange membranes is used. If it is necessary to concentrate impurities in a small volume, and electrodialysis is preferred among all membrane methods, because allows to obtain solutions with high concentrations, which cannot be achieved using baromembrane technologies.

Membrane technologies for processing solutions are environmentally friendly and efficient and allow solving such problems as the creation of closed technological cycles, as well as the return of valuable components to production, which reduces the environmental burden of production on the environment $[4,5]$. Therefore, it is urgent to increase the efficiency of membrane technologies. Electrodialysis allows to desalt and concentrate various technological solutions and wastewater which containing electrolytes [6]. Electrodialysis with bipolar membranes [7-9] or its combination with ion exchange [10] is often used to recover acids or heavy metal salts. A combination of ion exchange with classical electrodialysis is also used to recover sulfuric acid from wastewater generated during the processing of chalcopyrite [11]. In addition, electrodialysis and metathesis electrodialysis are used to recover organic acids [12]. However, the problem of separation of mixed solutions of electrolytes is still urgent. Despite the fact that in recent years there has been a large number of works devoted to imparting specific selectivity to membranes in the processes of electromembrane separation, the separation coefficients of ions of the same charge sign on such membranes have low values or membranes are experimental laboratory samples [13-16]. In addition, at current densities above the limiting value, the selectivity of such membranes is significantly reduced, which reduces the practical significance of the application of such processes in industry [17].

In this regard, a promising method for the separation of ternary electrolytes is the diffusion dialysis using ionexchange membranes, since it does not require high energy costs for its implementation. This separation method can have several advantages over electrodialysis. One can expect high efficiency of separation of acids and salts in the case of using anion-exchange membranes due to the extremely high mobility of hydrogen ions, which as a coion will determine the rate of diffusion transfer [18-20]. Such processes will be in demand for the processing of spent galvanic solutions, as well as in hydrometallurgical processes. In addition, diffusion dialysis has a number of advantages over electrodialysis - low energy consumption, simplicity of instrumental design, and the use of membranes of the same polarity [21]. In work [22], diffusion dialysis, electrodialysis, and electrodialysis were compared with bipolar membranes for the recovery of sulfuric acid and tetrabutylammonium. Despite the fact that bipolar electrodialysis requires significantly fewer membranes than diffusion dialysis, the costs of bipolar electrodialysis are very high due to the high cost of bipolar membranes and significant electricity consumption. Also, electrodialysis with ion-exchange membranes is used for processing organo-mineral mixtures [23]. To increase the efficiency of electrodialysis processing of acidic solutions, ionexchange membranes with various modifiers are used. Thus, the use of polyaniline for the modification of cationexchange membranes reduces the current efficiency and reduces energy consumption in the process of electrodialysis processing of sulfuric acid solutions [24].

The process of concentrating sulfuric acid with electrodes made of various materials was studied in [25]. It is shown that the graphite anode is stable at low current densities and provides a high current efficiency; however, at high current densities, the anode was destroyed. For the concentration of acids, it is preferable to use titanium electrodes coated with ruthenium dioxide or platinum. The use of rhodium-plated titanium electrodes in the process of $\mathrm{HI}$ concentration in the sulfur-iodine thermochemical cycle has also proven itself well [26].

At the Abinsk Electric Steel Works Ltd., during the production of copper-coated steel wire, electrochemical deposition of copper from a sulfuric acid solution is used, while the solution is contaminated with iron sulfate. With an increase in the concentration of iron (II) in the electrolyte above $50 \mathrm{~g} / \mathrm{L}$, the quality of the copper coating deteriorates and this electrolyte is replaced. In this case, it is necessary to dispose of a large amount of a solution containing $150 \mathrm{~g} / \mathrm{L} \mathrm{H}_{2} \mathrm{SO}_{4}$ and $20 \mathrm{~g} / \mathrm{L} \mathrm{Cu}^{2+}$ and $50 \mathrm{~g} / \mathrm{L} \mathrm{Fe}^{2+}$.

To create a closed technological cycle, it is necessary to separate sulfuric acid from metal salts and return it to production. Electrodialysis with standard ion-exchange membranes is unable to solve this problem due to the low separation factor of various electrolytes. High separation coefficients of metal sulfates and sulfuric acid are observed during diffusion dialysis through anion exchange membranes. However, there are a set of problems when dialysis is used to process such solutions. When carrying out dialysis in a countercurrent mode of circulation of solutions with a low flow rate, it is possible to recover sulfuric acid with a sufficiently high concentration of $60-70 \%$ of the original. A significant disadvantage is that with such a hydraulic mode, a low concentration gradient is maintained over the entire length of the dialysis machine. This leads to the need to increase the number of expensive anion-exchange membranes several times. When carrying out dialysis in distilled water with its frequent replacement, it is possible to intensify the process by maintaining a high concentration gradient. This leads to a decrease in the amount of required anion-exchange membranes, but the volume of regenerated acid is several times greater than that of the original solution. The acid thus obtained has a low concentration and is not suitable for reuse in the elec- 
trolytic copper refining. The use of electrodialysis concentration can increase the acid concentration to the desired level.

In this work, the process of electrodialysis concentration of sulfuric acid for its return to the production cycle was studied.

\section{Experimental}

The process of electrodialysis concentration of sulfuric acid was performed on a laboratory cell consisting of alternating 5 cation-exchange and 5 anion-exchange membranes with a working area of $5 \times 20 \mathrm{~cm}^{2}$, the gap between the membranes was $0.1 \mathrm{~cm}$. The volumetric flow rate through the desalination path was $8.6 \mathrm{~L} / \mathrm{h}$ (linear velocity $0.013 \mathrm{~m} / \mathrm{s}$ ). The concentration chambers were made without circulation of solution, which makes it possible to increase the concentration of the recovered sulfuric acid. Heterogeneous electrodialysis membranes Ralex ${ }^{\circledR} \mathrm{CMH}-\mathrm{PP}$ were used as the cation exchange membrane, and Ralex ${ }^{\circledR}$ AMH-PP as the anion exchange membrane (MEGA a.s., Czech Republic). This membranes was chosen because it is reinforced with an acid-resistant polypropylene mesh. Membranes MK-40 and MA-41, produced by LLC "Innovative Enterprise Shchekinoazot”, Tula Region, Russia are reinforced with capron, which is unstable in acidic solutions. The appearance of the electrodialysis cell is shown in Fig. 1a, the schematic drawing of the membrane package is shown in Fig. 1b. The concentration process was carried out in a potentiostatic mode at a voltage drop of 1$6 \mathrm{~V}$ to the pair chamber, the acid concentration at the inlet was varied from 1 to $10 \mathrm{~g} / \mathrm{L}$. The resulting concentrate was collected 1 time per hour, and the acid concentration was determined by acid-base titration. The concentration chambers of the cell are filled due to the transfer of hydration water together with ions, as well as due to the osmotic and electroosmotic transfer of water. Dotted arrows in Fig. 1b show non-selective proton leakage through the anion-exchange membrane, which makes it difficult to obtain a high concentration of acid.

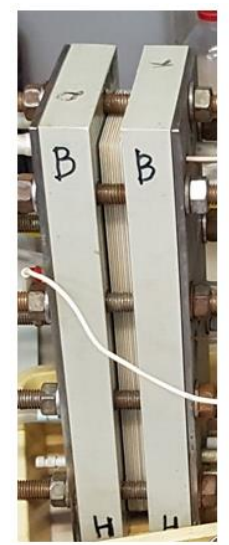

a

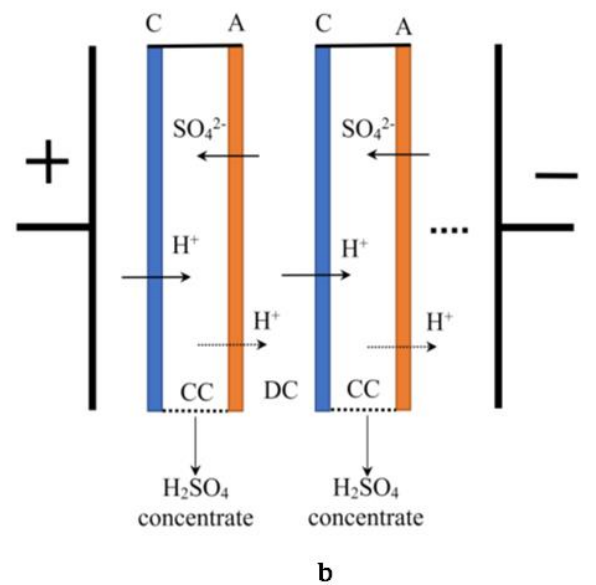

b
Fig. 1 The view of the electrodialysis cell (a) and the schematic drawing of the membrane package (b). C - cation exchange membrane, A - anion exchange membrane,

CC - concentration chamber, DC - desalination chamber

\section{Results and Discussion}

Fig. 2 shows the dependence of the volume of $\mathrm{H}_{2} \mathrm{SO}_{4}$ concentrate $\left(V_{k}\right)$ flowing out from the concentration chamber on the current density. All points fall on one curve, despite the fact that in different experiments the acid concentration at the inlet to the apparatus varied from 1 to $10 \mathrm{~g} / \mathrm{L}$.

Fig. 3 shows the dependence of the concentration of sulfuric acid in the concentrate $\left(C_{k}\right)$ on the voltage drop on the electrodialysis cell. The inlet concentration varied from $1.0 \mathrm{~g} / \mathrm{L}$ to $10 \mathrm{~g} / \mathrm{L}$. Analysis of Fig. 3 allows us to conclude that increasing the inlet acid concentration significantly affects the concentration of the resulting concentrate. In Fig. 4, the same data are plotted not from voltage drop, but from current density and all experimental points can be fitted by one curve. Thus, an increase in the acid concentration at the inlet of the electrodialysis cell increases the electrical conductivity of the desalting chambers, which leads to an increase in the current density and increases the concentration of sulfuric acid. Based on the experiments performed, the energy consumption for the concentration of sulfuric acid was determined and are shown in Table 1 . The data are given for various acid concentrations at the inlet to the apparatus $\left(C_{i n}\right)$ and voltage drop across the cell $(U)$. Analysis of the data in Table 1 allows us to conclude that when the voltage drop on the electrodialysis cell increases, the energy consumption for

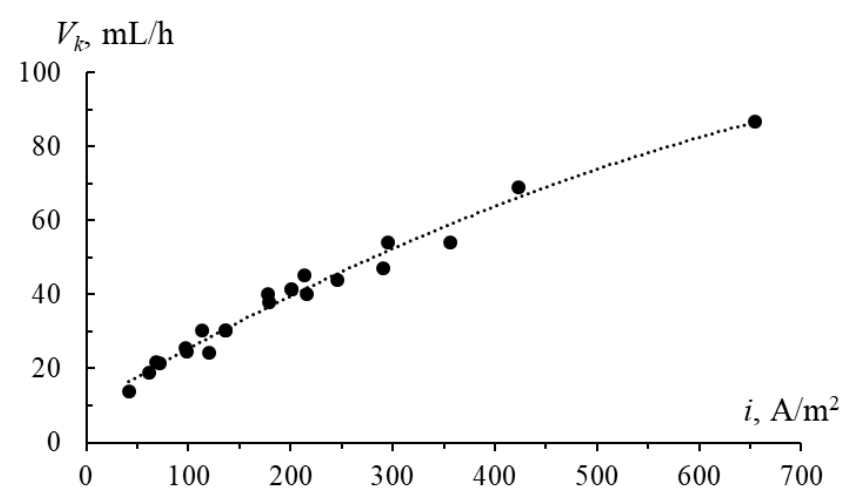

Fig. 2 Dependence of the volume of the formed sulfuric acid concentrate on the current density

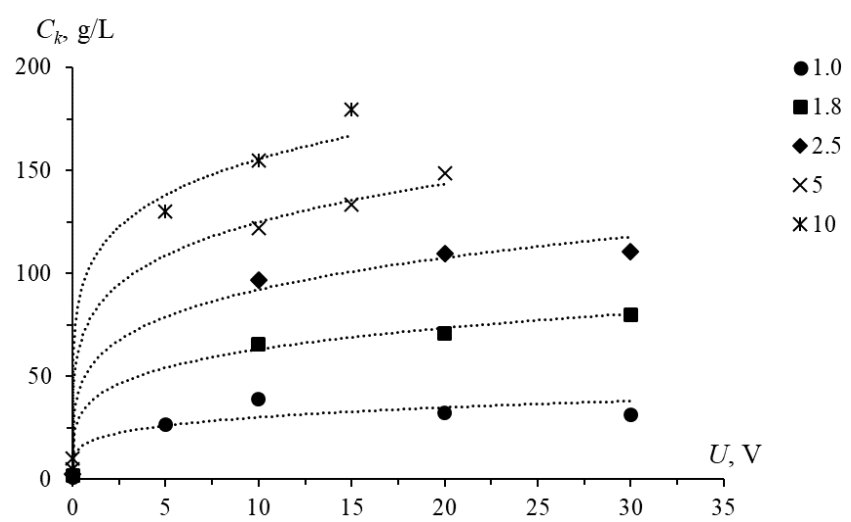

Fig. 3 Dependence of the concentration of recovered sulfuric acid on the voltage at the electrodialysis cell (the numbers in the legend show the concentration of sulfuric acid at the inlet to the apparatus, g/L) 


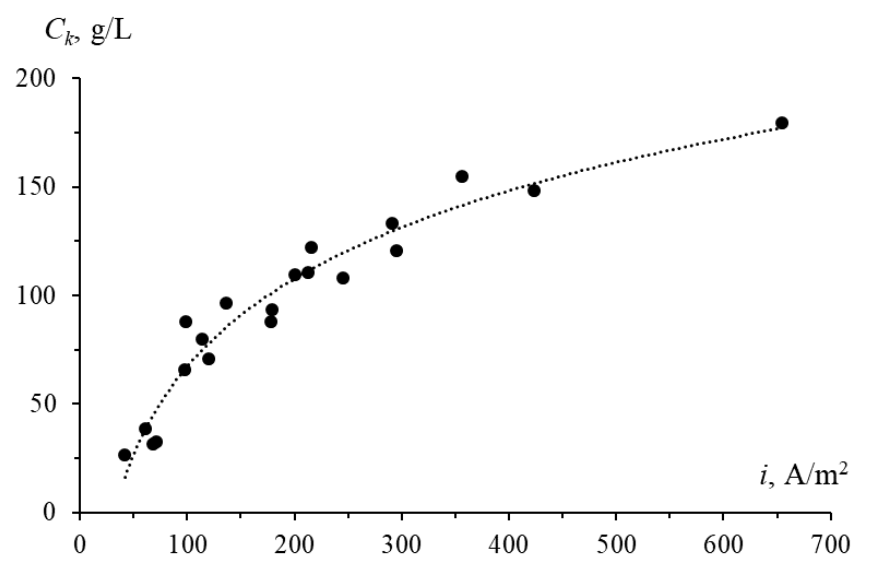

Fig. 4 Dependence of the concentration of sulfuric acid in the concentrate on the current density on the apparatus

Table 1 Energy consumption $(\mathrm{W} \cdot \mathrm{h} / \mathrm{mol})$ for the process of concentration of the sulfuric acid

\begin{tabular}{cccccc}
\hline \multirow{2}{*}{$C_{\text {in }}, \mathrm{g} / \mathrm{L}$} & \multicolumn{5}{c}{$U, \mathrm{~V}$} \\
\cline { 2 - 6 } & 5 & 10 & 15 & 20 & 25 \\
\hline 1.0 & 548 & 810 & - & 2006 & 2940 \\
1.8 & - & 565 & - & 1429 & 1794 \\
2.5 & - & 458 & - & 867 & 1258 \\
5.0 & & 429 & 680 & 1083 & - \\
10.0 & 219 & 449 & 616 & - & - \\
\hline
\end{tabular}

the sulfuric acid concentration process decreases. It should be noted that when the salts are concentrated, energy consumption usually increases with increasing voltage.

The anomalous dependence for sulfuric acid appears to be related to proton leakage through the anion exchange membranes (Fig. 1b), as well as acid loss by diffusion. Therefore, when the voltage is increased, due to the fact that the time required for the transfer of 1 mole of sulfuric acid is reduced, the energy consumption also decreases. The maximum possible voltage drop (and current density) is limited by the ohmic heating of the solution and the electrodialysis cell.

Since the concentration chambers are non-flowing, the composition of the solution in them is determined by the transfer of ions and water through cation and anion exchange membranes. The electrolyte and water flows can be described by the equations:

$$
\begin{aligned}
& j_{\mathrm{e}}=-P_{\mathrm{s}}\left(C_{\mathrm{k}}-C_{\mathrm{in}}\right)+\eta \frac{i}{F} \\
& j_{\mathrm{w}}=P_{\mathrm{w}}\left(C_{\mathrm{k}}-C_{\mathrm{in}}\right)+h \eta \frac{i}{F}
\end{aligned}
$$

where $j_{\mathrm{e}}$ is the electrolyte flow; $j_{\mathrm{w}}$ is the water flow; $P_{\mathrm{s}}=P_{\mathrm{s}}^{\mathrm{a}}+P_{\mathrm{s}}^{\mathrm{k}}, P_{\mathrm{w}}=P_{w}^{\mathrm{a}}+P_{w}^{\mathrm{k}}$ are the diffusion and osmotic permeability of the membrane pair, respectively; $h$ - salt hydration number, $h$ - current efficiency.

These equations can be linearized by dividing by $\Delta C=C_{\mathrm{k}}-C_{\mathrm{in}}:$

$$
\begin{aligned}
& \frac{j_{\mathrm{e}}}{\Delta C}=-P_{\mathrm{s}}+\frac{\eta}{F} \cdot \frac{i}{\Delta C} \\
& \frac{j_{\mathrm{w}}}{\Delta C}=P_{\mathrm{w}}+\frac{t_{w}}{F} \cdot \frac{i}{\Delta C}
\end{aligned}
$$

where $t_{w}=h \eta$ - water transport number.
Table 2 Calculated characteristics of the membrane pair Ralex ${ }^{\circledR}$ CMH-PP / Ralex ${ }^{\circledR}$ AMH-PP

\begin{tabular}{cccc}
\hline$\eta, \%$ & $P_{\mathrm{s}} \cdot 10^{8}, \mathrm{~m} / \mathrm{s}$ & $P_{\mathrm{w}} \cdot 10^{6}, \mathrm{~m} / \mathrm{s}$ & $t_{\mathrm{w}}, \mathrm{mol}\left(\mathrm{H}_{2} \mathrm{O}\right) / \mathrm{F}$ \\
\hline 14 & 1.38 & 1.78 & 1.15 \\
\hline
\end{tabular}

The data obtained were processed using the method of least squares in coordinates $\frac{j_{\mathrm{s}}}{\Delta C}-\frac{i}{\Delta C}$ and $\frac{j_{\mathrm{w}}}{\Delta C}-\frac{i}{\Delta C}$, which made it possible to determine the characteristics of the membrane pair.

Analysis of the data in Table 2 shows that the current efficiency values are low due to the proton leakage through the anion-exchange membrane and the high diffusion rate of acid from the concentration chamber to the desalination chamber. The calculated water transfer number is significantly lower than observed during salt concentration, which is caused to the relay-race mechanism of proton transfer.

\section{Conclusions}

Thus, the process of electrodialysis concentration of sulfuric acid has been studied using heterogeneous electrodialysis membranes Ralex ${ }^{\circledR}$ CMH-PP and Ralex ${ }^{\circledR}$ AMH-PP (MEGA a.s., Czech Republic) and it has been shown that it is possible to obtain a concentrate of up to $180 \mathrm{~g} / \mathrm{L}$, which makes it possible to use this acid in the production of copper-coated steel wire. The process of concentrating sulfuric acid must be carried out at the highest possible current density, because this reduces energy consumption, increases the concentration of regenerated sulfuric acid and reduces the required amount of membranes. The diffusion and osmotic permeability of the studied membranes have been determined, which will make it possible to predict the characteristics of industrial electrodialysis plants. The use of hybrid membrane technology, which includes dialysis separation of acids and salts and electrodialysis acid concentration, will allow it to be reused in the production cycle.

\section{Acknowledgments}

This study was funded by the Ministry of Education and Science of the Russian Federation (project No. FZEN2020-0022).

\section{References}

1. Kurniawan TA, Chan GYS, Lo WH, Babel S. Physico-chemical treatment techniques for wastewater laden with heavy metals. Chem Eng J. 2006;118(1):83-98. doi:10.1016/j.cej.2006.01.015

2. Gurreri L, Tamburini A, Cipollina A, Micale G. Electrodialysis Applications in Wastewater Treatment for Environmental Protection and Resources Recovery: A Systematic Review on Progress and Perspectives. Membranes. 2020;10(7):146. doi:10.3390/membranes10070146

3. Bazinet L, Geoffroy TR. Electrodialytic Processes: Market Overview, Membrane Phenomena, Recent Developments and Sustainable Strategies. Membranes. 2020;10(9):221. doi:10.3390/membranes10090221 
4. Panagopoulos A, Haralambous KJ, Loizidou M. Desalination brine disposal methods and treatment technologies - A review. Science of the Total Environment. 2019;693:133545. doi:10.1016/j.scitotenv.2019.07.351

5. Muhammad Y, Lee W. Zero-liquid discharge (ZLD) technology for resource recovery from wastewater: A review. Science of the Total Environment. 2019;681:551-63. doi:10.1016/j.scitotenv.2019.05.062

6. Yaroslavtsev AB, Nikonenko VV. Ion-exchange membrane materials: Properties, modification, and practical application. Nanotechnologies in Russia. 2009;4(3):137-59. doi:10.1134/S199507800903001X

7. Melnikov SS, Mugtamov OA, Zabolotsky VI. Study of electrodialysis concentration process of inorganic acids and salts for the two-stage conversion of salts into acids utilizing bipolar electrodialysis. Sep Purif Technol. 2020;235:1-10. doi:10.1016/j.seppur.2019.116198

8. Kishida M, Harato $\mathrm{T}$, Tokoro $\mathrm{C}$, Owada S. In situ remediation of bauxite residue by sulfuric acid leaching and bipolarmembrane electrodialysis. Hydrometallurgy. 2017;170:58-67. doi:10.1016/j.hydromet.2016.04.012

9. Wu X, Zhu H, Liu Y, Chen R, Qian Q, Van der Bruggen B. $\mathrm{Cr}$ (III) recovery in form of $\mathrm{Na}_{2} \mathrm{CrO}_{4}$ from aqueous solution using improved bipolar membrane electrodialysis. Journal of Membrane Science. 2020;604(118097). doi:10.1016/j.memsci.2020.118097

10. Heinonen J, Zhao Y, Van der Bruggen B. A process combination of ion exchange and electrodialysis for the recovery and purification of hydroxy acids from secondary sources. Separation and Purification Technology. 2020;240:116642. doi:10.1016/j.seppur.2020.116642

11. Aydin MI, Yuzer B, Hasancebi B, Selcuk H. Application of electrodialysis membrane process to recovery sulfuric acid and wastewater in the chalcopyrite mining industry. Desalination and Water Treatment. 2019;172:206-11. doi:10.5004/dwt.2019.25051

12. Handojo L, Wardani AK, Regina D, Bella C, Kresnowatia MTAP, Wenten IG. Electro-membrane processes for organic acid recovery. RSC Adv. 2019;9:7854-69. doi:10.1039/c8raog227c

13. Sata T, Sata T, Yang W. Studies on cation-exchange membranes having permselectivity between cations in electrodialysis. Journal of Membrane Science. 2002:206(1-2):31-6o. doi:10.1016/S0376-7388(01)00491-4

14. Ge L, Wu L, Wu B, Wang G, Xu T. Preparation of monovalent cation selective membranes through annealing treatment. Journal of Membrane Science. 2014;459:217-22. doi:10.1016/j.memsci.2014.02.025

15. Khoiruddin DA, Subagjo IGW. Surface modification of ionexchange membranes: Methods, characteristics, and performance. Journal of Applied Polymer Science. 2017;134(48):1-13. doi:10.1002/app.45540
16. Zhang Y, Paepen S, Pinoy L, Meesschaert B, Van Der Bruggen B. Selectrodialysis: Fractionation of divalent ions from monovalent ions in a novel electrodialysis stack. Separation and Purification Technology. 2012;88:191-201. doi:10.1016/j.seppur.2011.12.017

17. Zabolotskii VI, Lebedev KA, Orel IV. Specific Selectivity of Modified Ion-Exchange Membranes. Russian Journal of Electrochemistry. 2003;39(10):1130-3. doi:10.1023/A:1026187823767

18. Khan MI, Khraisheh M, Almomani F. Fabrication and characterization of pyridinium functionalized anion exchange membranes for acid recovery. Science of the Total Environment. 2019;686:90-6. doi:10.1016/j.scitotenv.2019.05.481

19. Gueccia R, Randazzo S, Chillura MD, Cipollina A, Micale G. Experimental investigation and modeling of diffusion dialysis for $\mathrm{HCl}$ recovery from waste pickling solution. Journal of Environmental Management. 2019;235:202-12. doi:10.1016/j.jenvman.2019.01.028

20. Wang K, Zhang Y, Huang J, Liu T, Wang J. Recovery of sulfuric acid from a stone coal acid leaching solution by diffusion dialysis. Hydrometallurgy. 2017;173:9-14. doi:10.1016/j.hydromet.2017.07.005

21. Regel-Rosocka M. A review on methods of regeneration of spent pickling solutions from steel processing. Journal of Hazardous Materials. 2010;177(1-3):57-69. doi:10.1016/j.jhazmat.2009.12.043

22. Zhang J, Niu D, Zhang X, Hu S. An economical process to recover sulfuric acid and tetrabutylammonium ions from acidic saline wastewater with organics. Desalination and Water Treatment. 2018;129:149-59. doi:10.5004/dwt.2018.23077

23. Loza NV, Loza SA, Romanyuk NA, Kononenko NA. Experimental and Theoretical Studies of Electrodialysis of Model Solutions Containing Aniline and Sulfuric Acid. Russ J Electrochem 2019;55:871-7. doi:10.1134/S102319351909009X

24. Loza NV, Loza SA, Kononenko NA, Magalyanov AV. Ion Transport in sulfuric acid solution through anisotropic composites based on heterogeneous membranes and polyaniline. Pet Chem. 2015;55:724-9. doi:10.1134/Sog65544115090054

25. Shetha B, Nath K. Effect of selected process parameters on the electrodialytic separation and concentration of sulfuric acid using graphite electrodes. Chemical Engineering Communications. 2020;207(3):295-305. doi:10.1080/00986445.2019.1587611 26. Caputo G, Balog I, Giaconia A, Sau S, Pozio A. Experimental Study for HIx Concentration by Electro-Electrodialysis (EED) Cells in theWater Splitting Sulfur-Iodine Thermochemical Cycle. ChemEngineering. 2019;3(2):50. doi: $10.3390 /$ chemengineering 3020050 